\title{
Cerebellum and brain stem volume loss in relapsing remission multiple sclerosis by MRI volumetry: relation to neurological disability score and number of relapses
}

\author{
Magdy Elzayady ${ }^{1,2}$, Naglaa Lotfy Debees ${ }^{2,3}$, Mohamed Khalii ${ }^{2,3}$ and Mohammed Mahmoud Dawoud ${ }^{2,3^{*}}$
}

\begin{abstract}
Background: MRI is the method of choice in the diagnosis of MS as well as in monitoring the disease activity. MRI volumetry is used to assess whole or regional brain volume loss which reflects neurodegenerative aspect of the disease and plays an important role in all stages of disease. The aim of this work is to study MRI volumetry in the evaluation of cerebellum and brain stem volume loss in RRMS patients and its correlation with neurological disability score and number of relapses.

Results: Volumes of whole brainstem, medulla, and pons showed a significant decrease in RRMS cases compared to controls $(p<0.05)$. Brainstem volume had a mean volume of 22.17 and $25.09 \mathrm{~cm}^{3}$ in cases and controls, respectively. However, midbrain volume showed no significant difference between cases and controls $(p=0.134)$. Volume of left cerebellar cortex showed a significant decrease in RRMS cases compared to controls $(p<0.001)$. It had mean volumes of 81.64 and $92.14 \mathrm{ml}$ in cases and controls, respectively, at left cerebellar hemisphere, while right cerebellar hemisphere cortex volumes were 80.37 and $91.97 \mathrm{ml}$ in cases and controls, respectively. Cerebellar white matter showed no significant volume decrease in cases and controls.

Conclusion: Volumetric MR imaging is an important tool for quantifying the MS disease, assesses MS activity, progression, and tissue loss. The degree and the pattern of atrophy on MRI images correlate significantly with the neurological disability score and number of relapses.
\end{abstract}

Keywords: MRI volumetry in RRMS, Brain stem volume loss in MS, Cerebellar volume loss in MS

\section{Background}

Multiple sclerosis (MS) is a central nervous system (CNS) chronic demyelinating, inflammatory disease with axonal loss. The development of lesions throughout the CNS is its distinguishing criteria. MS characterized by progressive CNS atrophy and is thought to be a better correlated with permanent disability than T2 lesion load [1].

\footnotetext{
* Correspondence: dr.m.dawoud82@gmail.com

${ }^{2}$ El-Geish Street, Tanta, Gharbya Governorate, Egypt

${ }^{3}$ Faculty of Medicine, Tanta University, El-Geish Street, Tanta, Gharbya

Governorate, Egypt

Full list of author information is available at the end of the article
}

It was believed that MS associated with loss of white matter (WM) volume, but recent studies have confirmed greater grey matter (GM) volume loss. Moreover, patients who converted into clinically definite MS over a period of 3 years develop significant brain volume loss, thus confirming early brain atrophy can present in some patients $[2,3]$.

The positive correlation between progression of MS and brain atrophy is widely accepted. Magnetic resonance imaging (MRI) studies of MS patients clarify that brain atrophy related to demyelination and axonal loss. Demyelination is potentially reversible process whereas axonal loss is not $[4,5]$. 
While there have been many studies focused on brain and spinal cord volume loss, relatively little researches have focused on volume loss of the brain stem and cerebellum in MS. The brain stem is a common site for MS affection which can cause vertigo, eye movement disorders, urinary problems, tremors, facial pain, hemiplegia, paralysis, and hearing problems. Many of these manifestations may develop early in MS [6].

The cerebellum is functionally and anatomically a fascinating but complex structure. The cerebellum has the highest growth rate of all brain structures during the late fetal and early postnatal life, reaching its adult cell count only by the age of 2 years. It is segregated in parallel cortico-nuclear sub-circuits that are integrated in various sensory-motor and cognitive-behavioral networks. Therefore, MS-related tissue damage of the cerebellum affects a magnitude of brain functions and significantly contributes to the development of disability $[7,8]$.

Brain volume measurements are correlated with the clinical status of patients and are important predictive feature of their clinical evolution. Progressive loss of regional or whole brain volume can be detected in vivo by MR imaging, mainly with the use of quantitative measures acquired by automated techniques [9].

MR imaging has become the modality of choice in evaluation of MS and is used to help the diagnosis and track the natural course of the disease. The ability to detect and characterize the disease burden, including occult microscopic disease invisible when using conventional MR techniques, has largely improved with the advent of newer quantitative MR techniques including volumetric MR imaging, diffusion tensor imaging (DTI), magnetization transfer imaging (MTI), and proton MR (1H-MR) spectroscopy. Today, MR imaging is the most important paraclinical tool for MS, and MR imaging-derived measures have been established as standard outcome markers to monitor the treatment response in various MS clinical trials [10].

There are various software programs to calculate volumetric changes and assess extension of atrophic changes in the affected regions that happen during a certain disease. One of these programs is 3D Slicer software which is a free open-source software application for medical image computing used to assess volumetric changes that occur in the brain stem and cerebellum in MS [11].

The aim of this work is to study MRI volumetry in the evaluation of cerebellum and brain stem volume loss in RRMS patients and its correlation with neurological disability score and number of relapses.

\section{Methods}

\section{Patients population}

This prospective study included 60 subjects (30 case groups, 30 control groups). Thirty patients (case group/ group I) diagnosed with RRMS by clinical examinations and conventional MRI according to modified McDonald's criteria referred to diagnostic radiology department from the neurology department throughout period extending from December 2017 to March 2020. Thirty healthy subjects (control group/group II) with age and sex distribution similar to case group were selected as control group, with no medical or neurological disorders. Patients with cardiac pacemaker, clipped aneurysm or cochlear implant, or who refuse examination were excluded from study.

Approval of Research Ethics Committee (REC) and informed written consent were obtained from all participants in the study after full explanation of the benefits and risks of the procedure. Privacy and confidentiality of all patient data were guaranteed. All data provision were monitored and used for scientific purpose only.

\section{All patients were subjected to the following Full neurological examination}

Magnetic resonance imaging (MRI) Magnetic resonance imaging was done for all patients using a 1.5 Tesla MRI system (GE sigma explorer).

a) MRI protocol

Sagittal 3D T1-weighted spoiled gradient (SPGR) utilizing the following parameters in Table 1.

Table 1 Parameters of volumetric MRI protocol

\begin{tabular}{ll}
\hline Imaging parameters & 3D T1W SPGR \\
\hline Plane & Sagittal \\
Mode & $3 \mathrm{D}$ \\
Pulse sequence & SPGR \\
Prep. time & $500 \mathrm{~ms}$ \\
TE & Minimum full \\
TR & $7.2 \mathrm{~ms}$ \\
FOV & $256 \times 256 \mathrm{~mm}$ \\
Phase FOV & 1.0 \\
Frequency & $16 \mathrm{kHz}$ \\
Slice thickness & $1.2 \mathrm{~mm}$ \\
Number of slices & 160 \\
Slice spacing & 0 \\
Flip angle & $10^{\circ}$ \\
Matrix & $192 \times 192$ \\
Freq DIR & $\mathrm{S} / \mathrm{l}$ \\
NEX & 1.0 \\
Shim & $\mathrm{Auto}$ \\
Phased array uniformity enhancement (PURE) & On \\
Surface coil intensity correction (SCIC) & Off \\
\hline & \\
\hline & \\
\hline
\end{tabular}


b) Image analysis

Volumetric analysis has been done by 3D Slicer software package version 4.6 using semi-automated technique to calculate the volumes of cerebellar gray matter, cerebellar white matter, midbrain, pons, medulla oblongata, and whole brain stem. 3D Slicer software is an open source medical image computing platform for biomedical research and freely downloadable. Semi-automatic slice-by-slice segmentations of every data set have been performed. As hardware platform, we used a computer with Intel Core i7-750 CPU, $4 \times 2.66 \mathrm{GHz}, 8 \mathrm{~GB}$ RAM, with Windows 10 Professional $\times 64$.

\section{c) Image interpretation}

Interpretation of MR images and volumetric analysis were done by two experienced radiologists with at least 5 years of experience in neuroradiology.

\section{Statistical analysis of the data}

Data were fed to the computer and analyzed using IBM SPSS software package version 20.0. Qualitative data were described using number and percent. Quantitative data were described using range (minimum and maximum), mean, standard deviation, and median. Comparison of MR volumetric findings with normal values was done using one sample $t$ test. Significance test results are quoted as two-tailed probabilities. Significance of the obtained results was judged at the $5 \%$ level.

\section{Results}

Case group (group I) included 30 patents with RRMS (18 female \& 12 male), their ages ranged from 24 to 38 years with a mean age of $30.93 \pm 3.67$ years. Control group (group II) included 30 healthy subjects (19 female and 11 male), their ages ranged from 25 to 38 years with a mean age of $31.13 \pm 3.62$ years. Most of the subjects included in the study were females $(60 \%$ in the cases group and $63.3 \%$ in the control group). Different body measurements were nearly the same in both groups including height (mean height $178.16 \pm 7.12$ in case group $\backslash 168.47 \pm 8.26$ in control group) and body weight (mean body weight $85.98 \pm 10.96$ in case group $\backslash 84.96 \pm$ 14.46 in control group), the above findings were listed in Table 2.

Pyramidal dysfunction was detected in 25 cases, sensory dysfunction (19 cases), cerebral dysfunction (11 cases), cerebellar dysfunction (18 cases), bowel and bladder dysfunction (16 cases), visual problems (22 cases), and mental problems ( 2 cases). More than one complains detected in the same patient. The disease duration ranged between 1 and 13 years with a mean disease duration was $6.78 \pm 3.17$ years. The EDSS score ranged
Table 2 Age and sex distribution in the studied subjects $(n=60)$ Age and sex distribution in the studied control group $(n=30)$

\begin{tabular}{|c|c|c|c|c|c|c|}
\hline \multirow{3}{*}{ Age in years } & \multicolumn{4}{|l|}{ Sex } & \multicolumn{2}{|c|}{ Total } \\
\hline & \multicolumn{2}{|c|}{ Male } & \multicolumn{2}{|c|}{ Female } & \multirow[b]{2}{*}{ No. } & \multirow[b]{2}{*}{$\%$} \\
\hline & No. & $\%$ & No. & $\%$ & & \\
\hline $25->30$ & 4 & 13.33 & 6 & 20 & 10 & 33.33 \\
\hline $30->35$ & 4 & 13.33 & 10 & 33.33 & 14 & 46.66 \\
\hline $35-\geq 40$ & 3 & 10 & 3 & 10 & 6 & 20 \\
\hline \multicolumn{7}{|c|}{ Age and sex distribution in the studied case group $(n=30)$} \\
\hline \multirow[t]{3}{*}{ Age in years } & \multicolumn{4}{|l|}{ Sex } & \multicolumn{2}{|c|}{ Total } \\
\hline & \multicolumn{2}{|c|}{ Male } & \multicolumn{2}{|c|}{ Female } & & \\
\hline & No. & $\%$ & No. & $\%$ & No. & $\%$ \\
\hline $25->30$ & 3 & 10 & 2 & 6.66 & 5 & 16.66 \\
\hline $30->35$ & 6 & 20 & 12 & 40 & 18 & 60 \\
\hline $35-\geq 40$ & 3 & 10 & 4 & 13.33 & 7 & 23.33 \\
\hline
\end{tabular}

from 0.5 to 5 with a mean of 2 . The number of relapses was ranges between 1 and 7 with a mean of 3 . These findings were listed in Table 3.

Magnetic resonance volumetry was done for all subjects (case and control groups) to assess volume of medulla oblongata, pons, midbrain, whole brain stem, left cerebellar white matter, left cerebellar grey matter, right cerebellar white matter, and right cerebellar grey matter.

The volume of medulla oblongata in the case group $\left(3.09-3.71 \mathrm{~cm}^{3}\right)$ with a mean volume of $3.41 \pm 0.25 \mathrm{~cm}^{3}$. In control group $\left(4.25-5.12 \mathrm{~cm}^{3}\right)$ with a mean volume of $4.71 \pm 0.45 \mathrm{~cm}^{3}$ with statistically significant difference between the two groups $(p=0.041)$. The volume of pons in case group $\left(11.42-14.03 \mathrm{~cm}^{3}\right)$ with a mean volume of $12.08 \pm 1.35 \mathrm{~cm}^{3}$. In the control group (12.66-16.51 $\mathrm{cm}^{3}$ ) with a mean volume of $14.16 \pm 1.64 \mathrm{~cm}^{3}$ with statistically significant difference between the two groups $(p=0.039)$. The volume of midbrain in the case group $\left(4.74-5.97 \mathrm{~cm}^{3}\right)$ with a mean volume of $5.37 \pm 0.45 \mathrm{~cm}^{3}$. In the control group (5.24-6.33 $\mathrm{cm}^{3}$ ) with a mean volume of $5.97 \pm 0.59 \mathrm{~cm}^{3}$ with no statistically significant difference between the two groups $(p=0.134)$. The

Table 3 Clinical presentations in the studied cases $(n=30)$

\begin{tabular}{lll}
\hline Variable & Frequency & Percentage (\%) \\
\hline Pyramidal dysfunction & 25 & 83.3 \\
Sensory dysfunction & 19 & 63.3 \\
Cerebral dysfunction & 11 & 36.7 \\
Cerebellar dysfunction & 18 & 60 \\
Bowel and bladder dysfunction & 16 & 53.3 \\
Visual problems & 22 & 73.3 \\
Mental problems & 2 & 6.7 \\
\hline
\end{tabular}


whole brain stem volume in the case group (19.11-25.4 $\mathrm{cm}^{3}$ ) with a mean volume of $22.17 \pm 2.37 \mathrm{~cm}^{3}$, in the control group $\left(22.46-28.1 \mathrm{~cm}^{3}\right)$ with a mean volume of $25.09 \pm 2.58 \mathrm{~cm}^{3}$ with statistically significant difference between the two groups $(p=0.025)$. Volumetric analysis measurements of brain stem were listed in Table 4.

The best cut-off value of the whole brain stem volume to detect volume loss between cases and controls was < $23.25 \mathrm{~cm}^{3}$. The area under the curve (AUC) at this point was 0.855 with $84 \%$ sensitivity, $86 \%$ specificity, $64 \%$ PPV, and $74 \%$ NPV as shown in Fig. 1.

The volume of left cerebellar white matter in the case group (18.86-24.1 $\left.\mathrm{cm}^{3}\right)$ with a mean volume of $21.75 \pm$ $2.87 \mathrm{~cm}^{3}$ and in the control group (19.06-25.21 $\mathrm{cm}^{3}$ ) with a mean volume of $22.04 \pm 3.27 \mathrm{~cm}^{3}$, no statistically significant difference between the two groups $(p=$ 0.264 ). The volume of left cerebellar cortex (grey matter) in the cases group $\left(76.33-86.52 \mathrm{~cm}^{3}\right)$ with a mean volume of $81.64 \pm 4.8 \mathrm{~cm}^{3}$ and in the control group $\left(84.39-102.17 \mathrm{~cm}^{3}\right)$ with a mean volume of $92.14 \pm 9.83$ $\mathrm{cm}^{3}$ with high statistically significant difference between the two groups $(p<0.001)$. Volumetric analysis measurements of left cerebellar hemisphere were listed in Table 5.

The right cerebellar white matter volume in the cases group $\left(18.65-24.08 \mathrm{~cm}^{3}\right)$ with a mean volume of $21.41 \pm$ $2.67 \mathrm{~cm}^{3}$ and in the control group (18.55-25.54 $\mathrm{cm}^{3}$ ) with a mean volume of $22.32 \pm 3.18 \mathrm{~cm}^{3}$ with no statistically significant difference between the two groups $(p=$ 0.174). The volume of right cerebellar cortex (grey matter) in the cases group $\left(75.92-85.11 \mathrm{~cm}^{3}\right)$ with a mean volume of $80.37 \pm 4.68 \mathrm{~cm}^{3}$ and in the control group $\left(84.36-101.87 \mathrm{~cm}^{3}\right)$ with a mean volume of $91.97 \pm 8.38$ $\mathrm{cm}^{3}$ with high statistically significant difference between the two groups $(p<0.001)$. Volumetric analysis measurements of right cerebellar hemisphere were listed in Table 5.

The best cut-off value of a mean cerebellar grey matter volume between cases and controls to detect volume loss was $<83.46 \mathrm{Scm}^{3}$. The area under the curve (AUC) at this point was 0.937 with $97.8 \%$ sensitivity, $95.7 \%$ specificity, 96.4\% PPV, and 94.3\% NPV. The best cut-off value of a mean cerebellar white matter volume to detect volume loss between control and case group was $<21.74$ $\mathrm{cm}^{3}$. The area under the curve (AUC) at this point was 0.774 with $62 \%$ sensitivity, $96 \%$ specificity, $88 \% \mathrm{PPV}$, and 95\% NPV as described in Figs. 2 and 3.

Thirteen cases with EDSS score of $(0.5-\leq 1)$ showed the following brain stem and cerebellar volume measurements; medulla $\left(3.5-3.71 \mathrm{~cm}^{3}\right)$, pons $\left(13-14.03 \mathrm{~cm}^{3}\right)$, midbrain $\left(5.5-5.97 \mathrm{~cm}^{3}\right)$, whole brain stem $(23.7-25.4$ $\mathrm{cm}^{3}$ ), left cerebellar white matter $\left(23-24.1 \mathrm{~cm}^{3}\right)$, left cerebellar grey matter $\left(83.55-86.52 \mathrm{~cm}^{3}\right)$, right cerebellar white matter $\left(22.5-24.08 \mathrm{~cm}^{3}\right)$, and right cerebellar grey matter $\left(82.7-85.11 \mathrm{~cm}^{3}\right)$. Eleven cases with EDSS score of $(<1-\leq 3)$ showed the following brain stem and cerebellar volume measurements: medulla (3.15-3.49 $\left.\mathrm{cm}^{3}\right)$, pons $\left(11.9-13.04 \mathrm{~cm}^{3}\right)$, midbrain $\left(5.03-5.51 \mathrm{~cm}^{3}\right)$, whole brain stem $\left(20.46-23.91 \mathrm{~cm}^{3}\right)$, left cerebellar white matter $\left(19.7-23.38 \mathrm{~cm}^{3}\right)$, left cerebellar grey matter $\left(78.15-84.02 \mathrm{~cm}^{3}\right)$, right cerebellar white matter $\left(21.62-23.09 \mathrm{~cm}^{3}\right)$, and right cerebellar grey matter $\left(77.5-82.73 \mathrm{~cm}^{3}\right)$. Six cases with EDSS score of $(<3-\leq$ $5)$ showed the following brain stem and cerebellar volume measurements: medulla $\left(3.09-3.22 \mathrm{~cm}^{3}\right)$, pons $\left(11.42-12.07 \mathrm{~cm}^{3}\right)$, midbrain $\left(4.7-5 \mathrm{~cm}^{3}\right)$, whole brain stem $\left(19.11-21.34 \mathrm{~cm}^{3}\right)$, left cerebellar white matter $\left(18.86-20.03 \mathrm{~cm}^{3}\right)$, left cerebellar grey matter $(76.3-79$

Table 4 Volumetric MRI analysis measurements of brain stem in studied subjects $(n=60)$

\begin{tabular}{|c|c|c|c|}
\hline & $\begin{array}{l}\text { Group I (case group) } \\
n=30\end{array}$ & $\begin{array}{l}\text { Group II (control group) } \\
n=30\end{array}$ & $p$ value \\
\hline \multicolumn{4}{|c|}{ Medulla oblongata $\left(\mathrm{cm}^{3}\right)$} \\
\hline Mean \pm SD & $3.41 \pm 0.25$ & $4.71 \pm 0.45$ & $0.041^{*}$ \\
\hline Range & $(3.09-3.71)$ & $(4.25-5.12)$ & \\
\hline \multicolumn{4}{|l|}{ Pons $\left(\mathrm{cm}^{3}\right)$} \\
\hline Mean \pm SD & $12.08 \pm 1.35$ & $14.16 \pm 1.64$ & $0.039^{*}$ \\
\hline Range & $(11.42-14.03)$ & $(12.66-16.51)$ & \\
\hline \multicolumn{4}{|c|}{ Midbrain $\left(\mathrm{cm}^{3}\right)$} \\
\hline Mean \pm SD & $5.37 \pm 0.45$ & $5.97 \pm 0.59$ & 0.134 \\
\hline Range & $(4.74-5.97)$ & $(5.24-6.33)$ & \\
\hline \multicolumn{4}{|c|}{ Whole brain stem $\left(\mathrm{cm}^{3}\right)$} \\
\hline Mean \pm SD & $22.17 \pm 2.37$ & $25.09 \pm 2.58$ & $0.025^{*}$ \\
\hline Range & $(19.11-25.4)$ & $(22.46-28.10)$ & \\
\hline
\end{tabular}

Data are expressed as mean $\pm \mathrm{SD}, p$ probability

*Statistically significant $(p<0.05)$ 


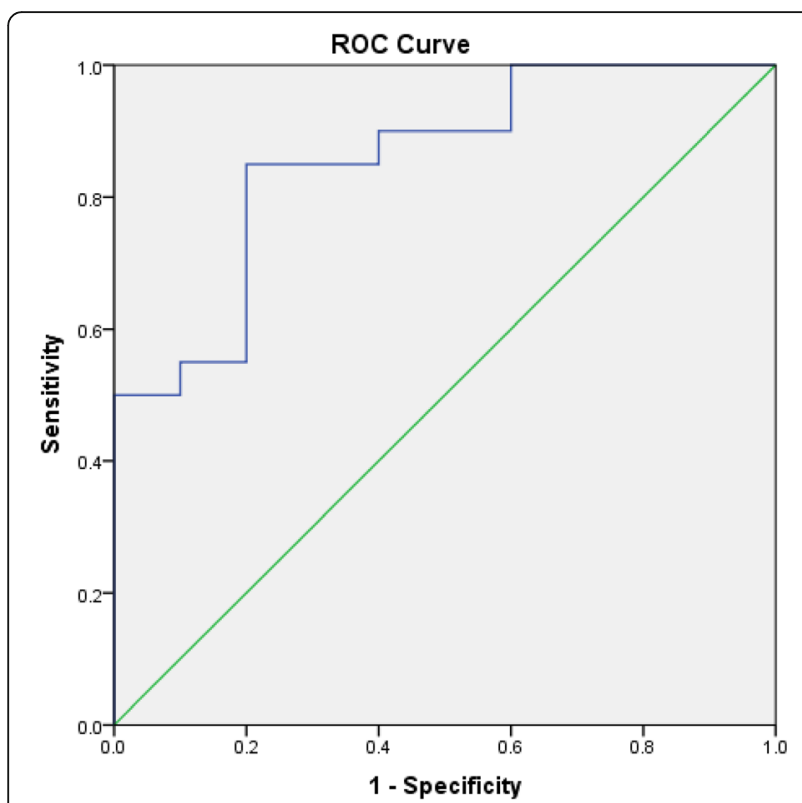

Fig. 1 ROC curve of prediction of whole brain stem volume loss in RRMS cases

$\left.\mathrm{cm}^{3}\right)$, right cerebellar white matter $\left(18.65-21.63 \mathrm{~cm}^{3}\right)$, and right cerebellar grey matter $\left(75.92-77.48 \mathrm{~cm}^{3}\right)$.

There was statistically significant moderate negative correlation between neurological disability and volumes of midbrain, pons, medulla oblongata, and the whole brain stem. Also, there was statistically significant strong negative correlation between neurological disability and volumes of cerebellar gray and white matter as shown in Table 6, Figs. 4, 5, and 6.

Nine cases with number of relapses (1 and 2) showed the following brain stem and cerebellar volume

Table 5 Volumetric MRI analysis measurements of cerebellum in studied subjects $(n=60)$

\begin{tabular}{|c|c|c|c|}
\hline & Group I (30 cases) & Group II (30 case) & $p$ value \\
\hline \multicolumn{4}{|c|}{ Left-cerebellum-white-matter $\left(\mathrm{cm}^{3}\right)$} \\
\hline Mean \pm SD & $21.75 \pm 2.87$ & $22.04 \pm 3.27$ & 0.264 \\
\hline Range & $(18.86-24.1)$ & $(19.06-25.21)$ & \\
\hline \multicolumn{4}{|c|}{ Left-cerebellum-cortex (grey matter) $\left(\mathrm{cm}^{3}\right)$} \\
\hline Mean \pm SD & $81.64 \pm 4.8$ & $92.14 \pm 9.83$ & $<0.001^{*}$ \\
\hline Range & $(76.33-86.52)$ & $(84.39-102.17)$ & \\
\hline \multicolumn{4}{|c|}{ Right-cerebellum-white-matter $\left(\mathrm{cm}^{3}\right)$} \\
\hline Mean \pm SD & $21.41 \pm 2.67$ & $22.32 \pm 3.18$ & 0.174 \\
\hline Range & $(18.65-24.08)$ & $(18.55-25.54)$ & \\
\hline \multicolumn{4}{|c|}{ Right-cerebellum-cortex (grey matter) $\left(\mathrm{cm}^{3}\right)$} \\
\hline Mean \pm SD & $80.37 \pm 4.68$ & $91.97 \pm 8.38$ & $<0.001^{*}$ \\
\hline Range & $(75.92-85.11)$ & $(84.36-101.87)$ & \\
\hline
\end{tabular}

Data are expressed as mean $\pm \mathrm{SD}, p$ probability

*Statistically significant $(p<0.05)$

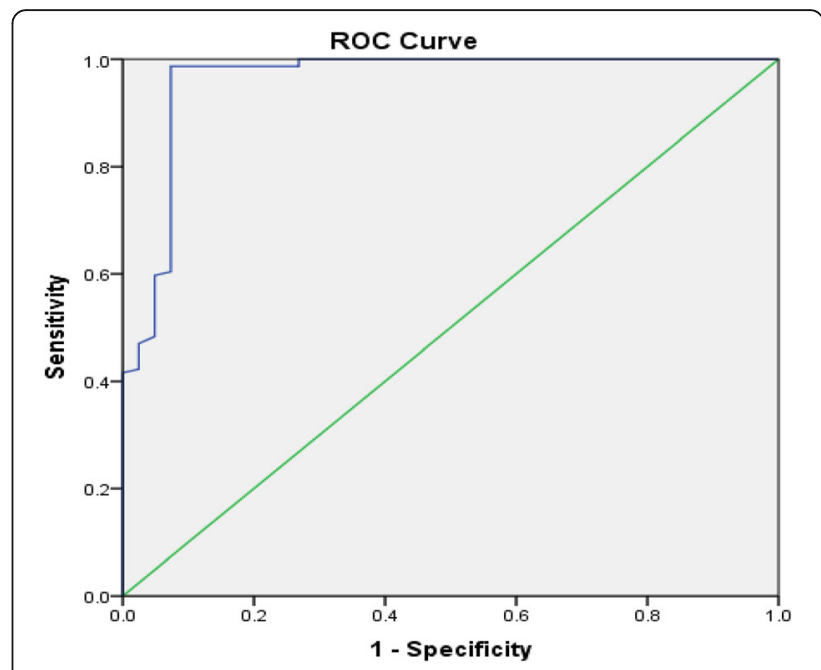

Fig. 2 ROC curve of prediction of cerebellar grey matter volume loss in RRMS cases

measurements: medulla $\left(3.2-3.71 \mathrm{~cm}^{3}\right)$, pons (13.4$\left.14.03 \mathrm{~cm}^{3}\right)$, midbrain $\left(5.7-5.97 \mathrm{~cm}^{3}\right)$, whole brain stem (24.7-25.4 $\left.\mathrm{cm}^{3}\right)$, left cerebellar white matter $(23.4-24.1$ $\left.\mathrm{cm}^{3}\right)$, left cerebellar grey matter $\left(82.78-86.52 \mathrm{~cm}^{3}\right)$, right cerebellar white matter $\left(23.5-24.08 \mathrm{~cm}^{3}\right)$, and right cerebellar grey matter $\left(83.7-85.11 \mathrm{~cm}^{3}\right)$. Fourteen cases with number of relapses of 3 and 4 showed the following brain stem and cerebellar volume measurements: medulla $\left(3.13-3.39 \mathrm{~cm}^{3}\right)$, pons $\left(11.4-13.34 \mathrm{~cm}^{3}\right)$, midbrain $\left(5.73-5.59 \mathrm{~cm}^{3}\right)$, whole brain stem $\left(21.46-23.91 \mathrm{~cm}^{3}\right)$, left cerebellar white matter $\left(19.7-23.68 \mathrm{~cm}^{3}\right)$, left cerebellar grey matter $\left(77.67-83.82 \mathrm{~cm}^{3}\right)$, right cerebellar

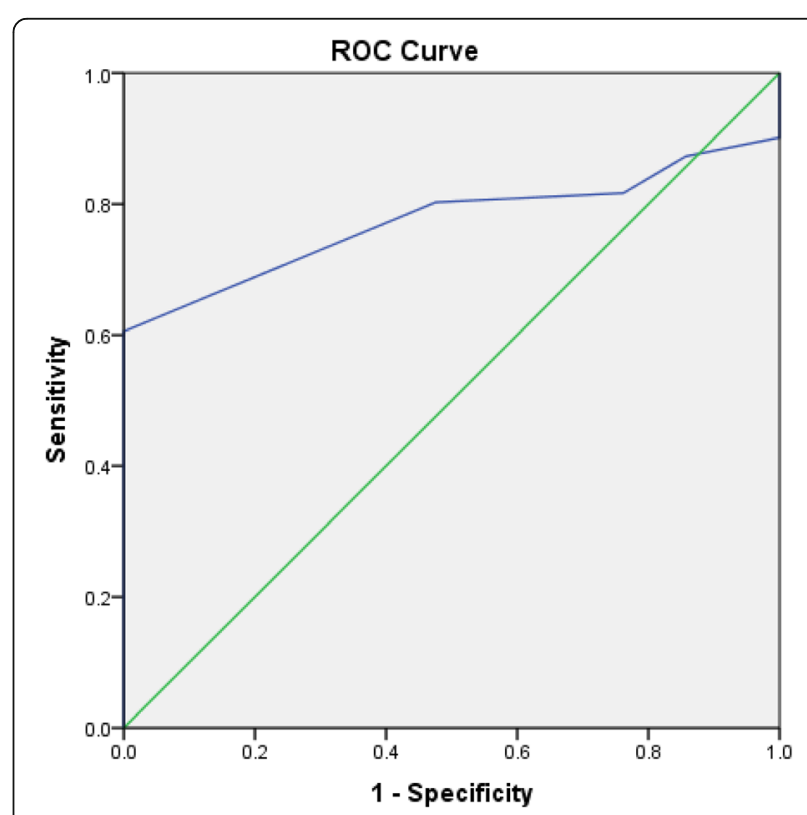

Fig. 3 ROC curve of prediction of cerebellar white matter volume loss in RRMS cases 
Table 6 Correlation between EDSS score and different brain stem, cerebellum volumetric MRI measurements

\begin{tabular}{|c|c|c|}
\hline \multicolumn{3}{|l|}{ EDSS } \\
\hline \multicolumn{3}{|l|}{$\overline{\text { Variable }}$} \\
\hline Medulla $\left(\mathrm{cm}^{3}\right)$ & -0.376 & $0.031^{*}$ \\
\hline Pons $\left(\mathrm{cm}^{3}\right)$ & -0.408 & $0.005^{*}$ \\
\hline Midbrain $\left(\mathrm{cm}^{3}\right)$ & -0.194 & 0.187 \\
\hline Whole brain stem $\left(\mathrm{cm}^{3}\right)$ & -0.459 & $<0.001^{*}$ \\
\hline Left-cerebellum-white-matter $\left(\mathrm{cm}^{3}\right)$ & -0.215 & 0.089 \\
\hline Left-cerebellum-cortex(grey matter) $\left(\mathrm{cm}^{3}\right)$ & -0.712 & $<0.001^{*}$ \\
\hline Right-cerebellum-white-matter $\left(\mathrm{cm}^{3}\right)$ & -0.254 & 0.067 \\
\hline Right-cerebellum-cortex (grey matter) $\left(\mathrm{cm}^{3}\right)$ & -0.644 & $<0.001^{*}$ \\
\hline
\end{tabular}

$r$ Spearman's correlation

*Statistically significant $(p<0.05)$

white matter $\left(21.37-23 \mathrm{~cm}^{3}\right)$, and right cerebellar grey matter $\left(76.5-83.73 \mathrm{~cm}^{3}\right)$. Seven cases with number of relapses of 5 to 7 showed the following brain stem and cerebellar volume measurements: medulla (3.09-3.12 $\left.\mathrm{cm}^{3}\right)$, pons $\left(11.42-12.26 \mathrm{~cm}^{3}\right)$, midbrain $\left(4.7-4.93 \mathrm{~cm}^{3}\right)$, whole brain stem $\left(19.11-21.1 \mathrm{~cm}^{3}\right)$, left cerebellar white matter $\left(18.86-19.73 \mathrm{~cm}^{3}\right)$, left cerebellar grey matter (76.3-78.9 $\left.\mathrm{cm}^{3}\right)$, right cerebellar white matter $(18.65-21.83$ $\left.\mathrm{cm}^{3}\right)$, and right cerebellar grey matter $\left(75.92-77.79 \mathrm{~cm}^{3}\right)$.

There was negative correlation between number of relapses and volumes of medulla, pons, midbrain, and whole brain stem. All these correlations were statistically significant except the midbrain. Also, there was statistically significant strong negative correlation between number of relapses and volume of cerebellar gray and white matter as shown in Table 7, Figs. 4, 5, and 6.

\section{Discussion}

Multiple sclerosis (MS) is an idiopathic demyelinating chronic disabling CNS illness common in young adults. MRI is a highly sensitive modality to detect lesions [12].

Using EDSS score alone as an outcome measure had several limitations, it is based on neurological examination, which is inherently subjective. Also, the clinical state of the patient does not reflect the true activity of MS in the CNS. Hence, an objective method is preferred by most practitioners [13].

Brain atrophy and lesion load on MRI are important biomarkers and associated with long-term disabilities [14]. Brain volume loss in MS patients occurs at a faster rate than in the healthy population: $0.5-1.0 \%$ vs. $0.1-0.3 \%$ per year. The exact mechanism of brain atrophy in MS is not clear, it may related to myelin and axonal loss [15].

Loss of medulla oblongata volume is associated with spinal cord damage and disability in a cohort of MS patients with a mean disease duration of 7.1 years, supporting that medulla atrophy is an important pathology in MS [16].
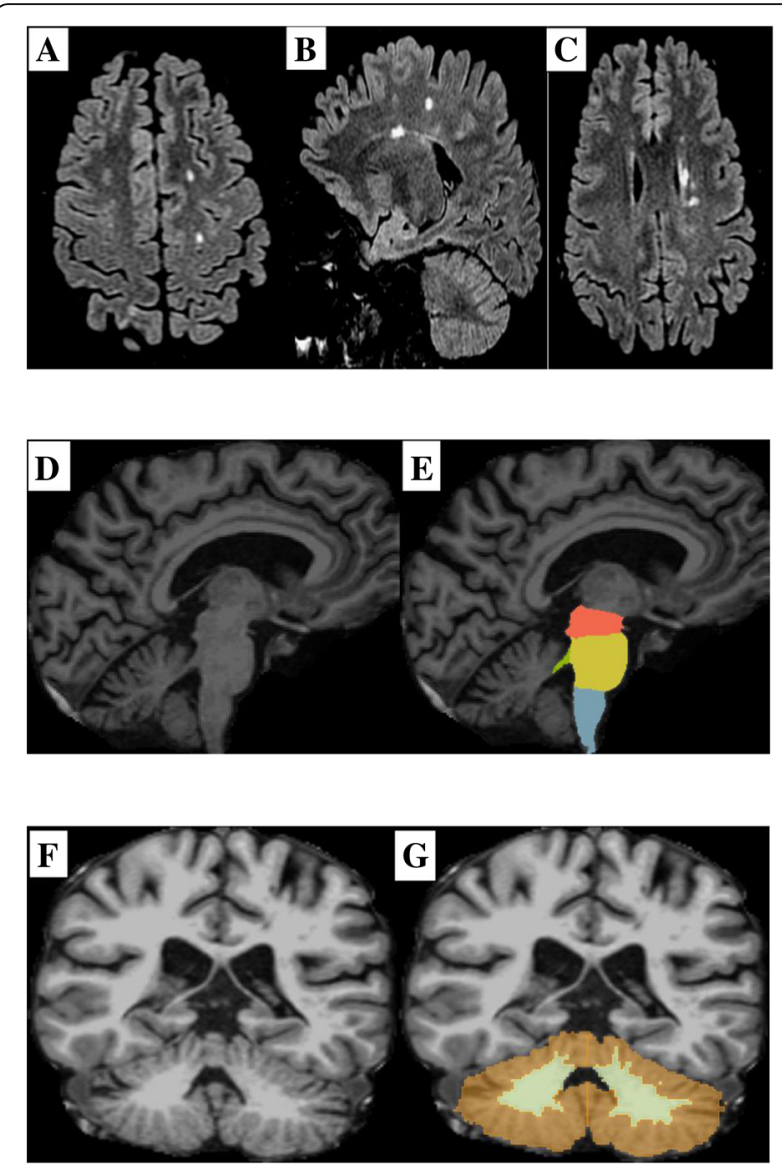

Fig. 4 A 29-year-old male patient with RRMS, EDSS score of 2, and a relapse rate of 2, complaining of sensory and pyramidal dysfunction. Axial and sagittal Flair sequences $(\mathbf{a}-\mathbf{c})$ showed multiple plaques of high SI seen at both parietal lobes; in periventricular white matter, pericallosal areas and centeum semiovale. The periventricular plaques are perpendicular to the ventricle giving Dawson's finger appearance. 3D T1WI in sagittal view (d, e) for brain stem segmentation and in coronal view $(\mathbf{f}, \mathbf{g})$ for cerebellar white and grey matter segmentation; (d, $\mathbf{f})$ raw unprocessed T1W image, $(\mathbf{e}, \mathbf{g})$ 3D T1 image after processing with 3D Slicer with colored segmented brain stem and cerebellum. The brain stem and cerebellar segmentation results showed the following data: midbrain $5.82\left(\mathrm{~N} 5.24-6.33 \mathrm{~cm}^{3}\right)$, pons $12.83\left(\mathrm{~N} 12.66-16.51 \mathrm{~cm}^{3}\right)$, medulla 3.87 ( $\left.\mathrm{N} 4.25-5.12 \mathrm{~cm}^{3}\right)$, whole brain stem $22.52\left(\mathrm{~N} 22.46-28.10 \mathrm{~cm}^{3}\right)$, left cerebellar white matter $23.47\left(\mathrm{~N} 19.06-25.21 \mathrm{~cm}^{3}\right)$, left cerebellar grey matter $83.94\left(\mathrm{~N} 84.39-102.17 \mathrm{~cm}^{3}\right)$, right cerebellar white matter $22.82\left(\mathrm{~N} 18.55-25.54 \mathrm{~cm}^{3}\right)$, and right cerebellar grey matter $83.16\left(\mathrm{~N} 84.36-101.87 \mathrm{~cm}^{3}\right)$. Patient with EDSS score of 2 and a relapse rate of 2 had a moderate decrease in the volumes of the medulla and cerebellar grey matter bilaterally

MS is the most common cause of non-traumatic disability in young adults typically begins at the ages of 20-40 years. Also, women are affected approximately twice as often as men [17]. We reported in current study predominant female affection $(60 \%$ in the cases group and $63.3 \%$ in the control group) with a mean age of 30.93 years in cases group and $31.13 \pm 3.62$ years in control group. 

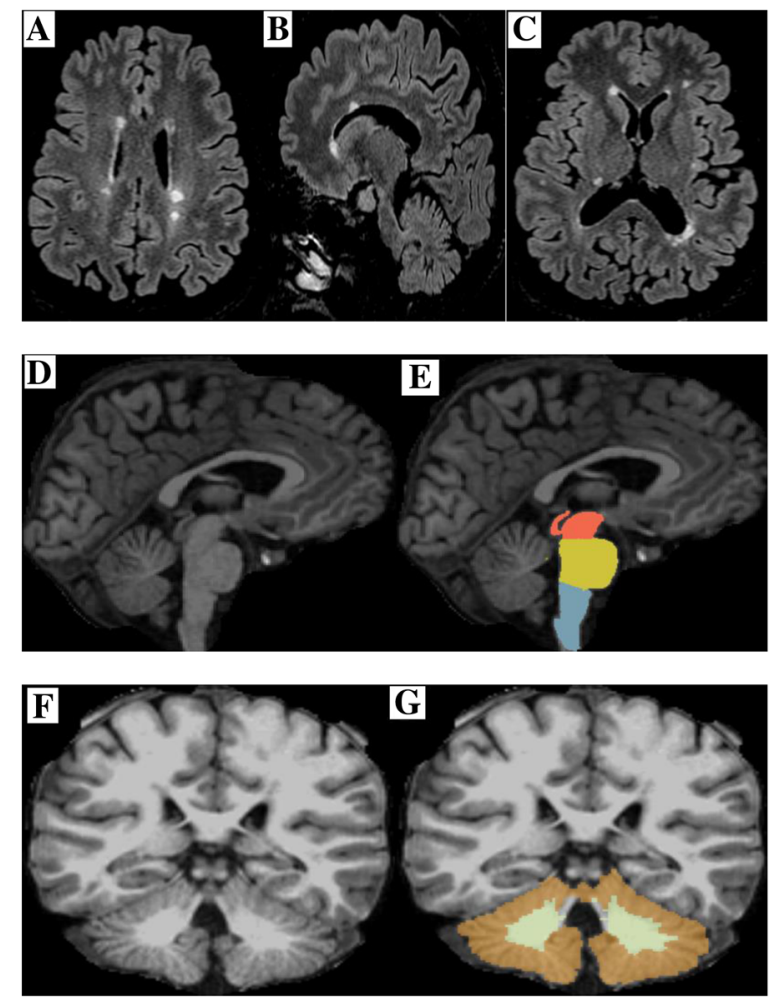

Fig. 5 A 25-year-old female patient aged 25 years old with RRMS, EDSS score of 0.5 , and a relapse rate of 1, complaining of pyramidal dysfunction. Axial and sagittal Flair sequences (a-c) showed multiple plaques of high SI seen at both parietal lobes; in periventricular white matter, pericallosal areas right deep white matter (basal ganglia). 3D T1W images in sagittal view $(\mathbf{d}, \mathbf{e})$ for brain stem segmentation and in coronal view $(\mathbf{f}, \mathbf{g})$ for cerebellar grey and white matter segmentation; (d, $\mathbf{f})$ raw unprocessed T1W image, (e, g) 3D T1image after processing with 3D Slicer with colored segmented brain stem and cerebellum structures. The brain stem and cerebellum segmentation results showed the following data: midbrain 5.9 (N 5.24-6.33 $\left.\mathrm{cm}^{3}\right)$, pons $13.85\left(\mathrm{~N} 12.66-16.51 \mathrm{~cm}^{3}\right)$, medulla $3.63\left(\mathrm{~N} 4.25-5.12 \mathrm{~cm}^{3}\right)$, whole brain stem was $23.38(\mathrm{~N}$ $\left.22.46-28.10 \mathrm{~cm}^{3}\right)$, left cerebellar white matter 24 (N 19.06-25.21 $\left.\mathrm{cm}^{3}\right)$, left cerebellar grey matter $84.59\left(\mathrm{~N} 84.39-102.17 \mathrm{~cm}^{3}\right)$, right cerebellar white matter $23.7\left(\mathrm{~N} 18.55-25.54 \mathrm{~cm}^{3}\right)$, and right cerebellar grey matter $84.5\left(\mathrm{~N} 84.36-101.87 \mathrm{~cm}^{3}\right)$. Patient with EDSS score of 0.5 and a relapse rate of 1 had a mild decrease in the volume of the medulla oblongata only

In the current study, volumes of the whole brainstem, medulla, and pons showed a significant decrease in MS cases compared to control cases $(p<0.05)$. Brainstem volume had a mean volume of 22.17 and $25.09 \mathrm{~cm}^{3}$ in cases and control cases, respectively. However, midbrain volume was not significantly different between cases and controls $(p=0.134)$.

Daams et al. [18] reported a 5.2\% normalized brain volume reduction in MS patients compared to healthy controls. Normalized brainstem volume was significantly decreased in MS cases $(27.71 \mathrm{ml})$ compared to control cases $(29.6 \mathrm{ml})$. In contrast to the present study, Lee
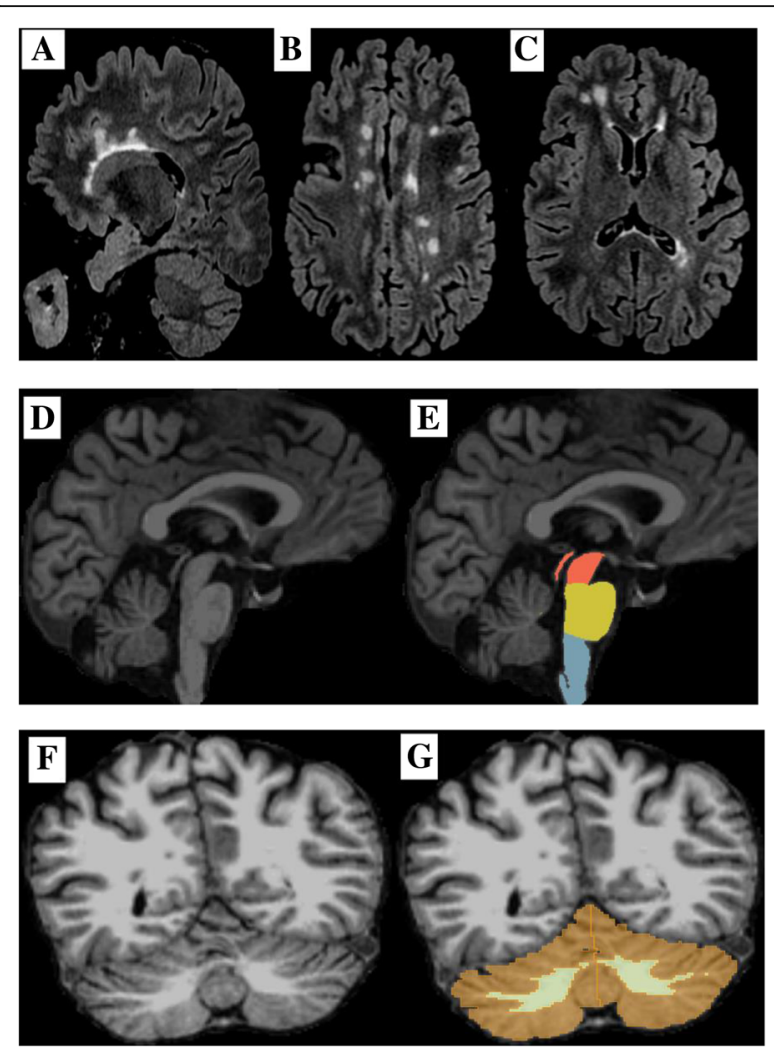

Fig. 6 A 35-year-old female patient with RRMS, EDSS score of 4, and a relapse rate of 6 , complaining of visual problems, cerebellar dysfunction, bowel, and bladder dysfunction. Axial and sagittal Flair sequences (a-c) showed multiple plaques of high SI at both parietal lobes; in periventricular white matter, pericallosal and callosomarginal areas, juxtacortical junction, and centeum semiovale. The

periventricular plaques are perpendicular to the ventricle giving Dawson's finger appearance. 3D T1W images in sagittal view (d, e) for brain stem segmentation and in coronal view $(\mathbf{f}, \mathbf{g})$ for cerebellar grey and white matter segmentation; $(\mathbf{d}, \mathbf{f})$ raw unprocessed T1W image, $(\mathbf{e}$, g) 3D T1image after processing with 3D Slicer with colored segmented brain stem and cerebellum structures. The brain stem and cerebellum segmentation results showed the following data: midbrain 5.02 ( $\mathrm{N}$ 5.24-6.33 $\mathrm{cm}^{3}$ ), pons $11.7\left(\mathrm{~N} 12.66-16.51 \mathrm{~cm}^{3}\right)$, medulla $3.1(\mathrm{~N} 4.25-$ $5.12 \mathrm{~cm}^{3}$ ), whole brain stem $19.82\left(\mathrm{~N} 22.46-28.10 \mathrm{~cm}^{3}\right)$, left cerebellar white matter $19.42\left(\mathrm{~N} 19.06-25.21 \mathrm{~cm}^{3}\right)$, left cerebellar grey matter $76.57\left(\mathrm{~N} 84.39-102.17 \mathrm{~cm}^{3}\right)$, right cerebellar white matter $20.61(\mathrm{~N}$ $\left.18.55-25.54 \mathrm{~cm}^{3}\right)$, and right cerebellar grey matter 76.07 (N 84.36$101.87 \mathrm{~cm}^{3}$ ). Patient with EDSS score of 4 and a relapse rate of 6 had a minimal decrease in the volume of the midbrain, severe decrease in the volumes of the pons, medulla, whole brain stem, and cerebellar grey matter bilaterally

et al. [14] reported as regards medulla oblongata volume, there was no significant difference between cases and controls (4.33 in MS vs. $4.35 \mathrm{~cm}^{3}$ in controls $-p>0.05$ ). There was a significant decrease in the size of pons and midbrain volumes in MS cases compared to controls ( $p$ $<0.05$ ). The normalized volumes of whole brainstem were significantly reduced in MS subjects compared to controls. Midbrain had mean sizes of $5.5-6 \mathrm{~cm}^{3}$, 
Table $\mathbf{7}$ Correlation between number of relapses and different brain stem, cerebellum volumetric MRI measurements

\begin{tabular}{lll}
\hline Number of relapses & & \\
\hline Variable & $\boldsymbol{R}$ & $\boldsymbol{p}$ \\
\hline Medulla $\left(\mathrm{cm}^{3}\right)$ & -0.402 & $0.009^{*}$ \\
Pons $\left(\mathrm{cm}^{3}\right)$ & -0.475 & $0.001^{*}$ \\
Midbrain $\left(\mathrm{cm}^{3}\right)$ & -0.213 & 0.132 \\
Whole brain stem $\left(\mathrm{cm}^{3}\right)$ & -0.657 & $<0.001^{*}$ \\
Left-cerebellum-white-matter $\left(\mathrm{cm}^{3}\right)$ & -0.187 & 0.324 \\
Left-cerebellum- grey matter $\left(\mathrm{cm}^{3}\right)$ & -0.661 & $<0.001^{*}$ \\
Right-cerebellum-white-matter $\left(\mathbf{c m}^{3}\right)$ & -0.303 & 0.102 \\
Right-cerebellum-grey matter $\left(\mathrm{cm}^{3}\right)$ & -0.655 & $<0.001^{*}$ \\
\hline
\end{tabular}

$r$ Spearman's correlation

*Statistically significant $(p<0.05)$

whereas pons had mean sizes of $13.22-14.05 \mathrm{~cm}^{3}$ in MS cases and controls, respectively.

In the present study, volume of left cerebellar hemisphere cortex showed a significant decrease in MS cases compared to controls $(p<0.001)$. It had mean volumes of 81.64 and $92.14 \mathrm{~cm}^{3}$ in cases and controls, respectively, while right cerebellar hemisphere cortex volumes were 80.37 and $91.97 \mathrm{~cm}^{3}$ in cases and controls, respectively. On the contrary, cerebellar white matter showed no significant volume decrease in cases and controls.

These results agreed with Anderson et al. [19], and they reported that volume of cerebellar white matter not statistically different between MS cases and controls $\left(20.8 \mathrm{~cm}^{3}\right.$ in RRMS, $18.9 \mathrm{~cm}^{3}$ in PPMS, and $20.4 \mathrm{~cm}^{3}$ in controls). However, PPMS had lower cerebellar grey matter volumes $\left(93.3 \mathrm{~cm}^{3}\right)$ compared to RRMS (97.2 $\left.\mathrm{cm}^{3}\right)$, and healthy controls $\left(97.5 \mathrm{~cm}^{3}\right)$.

In contrast to current study, Ge Y et al. [20] reported a significant loss of cerebellar white matter rather than gray matter in the early stage of MS which might indicate a different mechanism of atrophy in MS versus other neurodegenerative diseases. Lee et al. [14] reported that there was no significant difference in normalized cerebellar volume between MS cases and controls (0.119 vs. 0.117 in $\mathrm{MS}$ and controls, respectively $-p>0.05$ ). Unfortunately, they did not assess both white and grey matter volumes separately.

As regarding brain stem volume, we reported MRI sensitivity and specificity of 84 and $86 \%$, respectively, with an accuracy of $82 \%$ by using a cut-off value of $23.25 \mathrm{~cm}^{3}$. Also using a cut-off value of $83.46 \mathrm{~cm}^{3}$ for cerebellar grey matter, MRI had sensitivity and specificity of 87.8 and $95.7 \%$, respectively, with an accuracy of $95.2 \%$.

Daams et al. [18] reported a significant negative correlation between EDSS score and normalized brainstem volume $(r=-0.293-p<0.001)$. Also, between EDSS score and normalized cerebellar volume $(r=-0.242-p$ $<0.01)$. Lee et al. [14] reported normalized brainstem volume showed a moderate to strong positive correlation with normalized supratentorial brain volume $(p=0.027)$. In the present study, EDSS score and number of relapses showed a significant negative correlation with medulla, pons, whole brain stem volumes, in addition to both right and left cerebellar cortical volumes $(p<0.05)$ and could be used a predictor for disease severity in such cases.

Our study had several limitations; small sample size, study design, and imaging protocol did not include mean upper cervical cord area measurement, which has been reported to be an important predictor of motor dysfunction and disability in MS subjects. Moreover, the effect of treatment on brainstem and cerebellar volumes should have been assessed. Therefore, more studies handling the previous parameters should be conducted in the near future.

\section{Conclusion}

Volumetric MR imaging is an important tool for quantifying the MS disease, assess MS activity, progression, and tissue loss. The degree and the pattern of atrophy on MRI images correlate significantly with the neurological disability score and number of relapses.

\section{Abbreviations}

1H-MR: Proton MR; 3D: Three dimensions; AUC: Area under the curve; CNS: Central nervous system; DTI: Diffusion tensor imaging; EDSS: Expanded disability status scale; GM: Grey matter; MRI: Magnetic resonance imaging; MS: Multiple sclerosis; MTI: Magnetization transfer imaging; NPC: Negative predictive value; PPV: Positive predictive value; PURE: Phased array uniformity enhancement; REC: Approval of research ethics committee; RRMS: Relapsing remission relapse; SCIC: Surface coil intensity correction; SPGR: Sagittal 3D T1weighted spoiled gradient; WM: White matter

\section{Acknowledgements}

The authors acknowledge all the participants for their cooperation and patience.

\section{Authors' contributions}

MD suggested the research idea, ensured the original figures and data in the work, minimized the obstacles to the team of work, correlated the study concept and design and had the major role in analysis, ME collected data in all stages of manuscript, performed data analysis. ND supervised the study with significant contribution to design the methodology, manuscript revision, and preparation. MK correlated the clinical data of patient and matched it with the findings, drafted and revised the work. All authors read and approved the final manuscript for submission.

Funding

No funding. Not applicable for this section.

\section{Availability of data and materials}

The authors confirm that all data supporting the finding of the study are available within the article, and the raw data and data supporting the findings were generated and available at the corresponding author on request.

\section{Ethics approval and consent to participate}

Informed written consents taken from the patients and healthy volunteers, the study was approved by ethical committee of Tanta University Hospital, Faculty of Medicine. Committee's reference number: 31619/06/17. 


\section{Consent for publication}

All participants included in the research gave written consent to publish the data included in the study.

\section{Competing interests}

The authors declare that they have no competing of interests.

\section{Author details}

${ }^{1}$ Samanoud Central Hospital, Samanoud, Gharbya Governorate, Egypt. ${ }^{2}$ El-Geish Street, Tanta, Gharbya Governorate, Egypt. ${ }^{3}$ Faculty of Medicine, Tanta University, El-Geish Street, Tanta, Gharbya Governorate, Egypt.

Received: 11 November 2020 Accepted: 14 December 2020

Published online: 05 January 2021

\section{References}

1. Tomos C, Cris C, Christopher T (2015) MRI-based measurement of brain stem cross-sectional area in relapsing-remitting Multiple Sclerosis. J Neuroimaging 25:1002-1006

2. Quarantelli M, Ciarmiello A, Morra VB et al (2003) Brain tissue volume changes in relapsing-remitting multiple sclerosis: correlation with lesion load. J Neuroimage 18(2):360-366

3. Dalton CM, Chard DT, Davies GR et al (2004) Early development of multiple sclerosis is associated with progressive grey matter atrophy in patients presenting with clinically isolated syndromes. Brain J 127(Pt 5):1101-1107

4. Paz Soldán MM, Raman MR, Gamez JD et al (2015) Correlation of brain atrophy, disability and spinal cord atrophy in a Murine Model of Multiple Sclerosis. J Neuroimaging 25(4):595-599

5. Miller DH, Barkhof F, Frank JA et al (2002) Measurement of atrophy in multiple sclerosis: pathological basis, methodological aspects and clinical relevance. Brain J 125:1676-1695

6. Magnano I, Pes GM, Pilurzi G et al (2014) Exploring brainstem function in multiple sclerosis by combining brain stem reflexes, evoked potentials, clinical and MRI investigations. Clin Neurophysiology J 125:2286-2296

7. Weier K, Banwell B, Cerasa A et al (2015) The role of the cerebellum in Multiple Sclerosis. The Cerebellum J 14(3):364-374

8. Eriksson M, Andersen O, Runmarker B (2003) Long-term follow up of patients with clinically isolated syndromes, relapsing-remitting and secondary progressive multiple sclerosis. Multiple Sclerosis J 9(3):260-274

9. Sastre-Garriga J, Pareto D, Rovira A (2017) Brain atrophy in multiple sclerosis clinical relevance and technical aspects. Neuroimaging Clin N Am J 27(2): 289-300

10. Ge Y (2006) Multiple sclerosis: the role of MR imaging. Am J Neuroradiol 27(6):1165-1176

11. Fedorov A, Beichel R, Kalpathy-Cramer J et al (2012) 3D Slicer as an image computing platform for the quantitative imaging network. J Magnetic Resonance Imaging 30(9):1323-1341

12. Habek M (2013) Evaluation of brainstem involvement in multiple sclerosis. Expert review of neurotherapeutics 13(3):299-311

13. Filippi M (2015) MRI measures of neurodegeneration in multiple sclerosis: implications for disability, disease monitoring, and treatment. J Neurol 262(1):1-6

14. Lee C, Mak HK, Chiu P et al (2018) Differential brainstem atrophy patterns in multiple sclerosis and neuromyelitis optica spectrum disorders. J Magnetic Resonance Imaging 47(6):1601-1169

15. Marciniewicz E, Pokryszko-Dragan A, Podgórski P et al (2019) Quantitative magnetic resonance assessment of brain atrophy related to selected aspects of disability in patients with multiple sclerosis: preliminary results. Polish J Radiol 84:171-178

16. Liptak Z, Berger A, Sampat M et al (2008) Medulla oblongata volume: a biomarker of spinal cord damage and disability in multiple sclerosis. Am J Neuroradiol 29(8):1465-1470

17. Tullman MJ (2013) Overview of the epidemiology, diagnosis, and disease progression associated with multiple sclerosis. Am J Managed Care 19(2 Suppl):15-20

18. Daams M, Steenwijk MD, Wattjes MP et al (2015) Unraveling the neuroimaging predictors for motor dysfunction in long-standing multiple sclerosis. Neurology J 85(3):248-255

19. Anderson V, Wheeler-Kingshott C, Abdel-Aziz K et al (2011) A comprehensive assessment of cerebellar damage in multiple sclerosis using diffusion tractography and volumetric analysis. Multiple Sclerosis J 17(9): 1079-1087

20. Ge Y, Grossman RI, Udupa JK et al (2001) Brain atrophy in relapsingremitting multiple sclerosis: fractional volumetric analysis of gray matter and white matter. J Radiol 220(3):606-610

\section{Publisher's Note}

Springer Nature remains neutral with regard to jurisdictional claims in published maps and institutional affiliations.

\section{Submit your manuscript to a SpringerOpen ${ }^{\circ}$ journal and benefit from:}

- Convenient online submission

- Rigorous peer review

- Open access: articles freely available online

High visibility within the field

- Retaining the copyright to your article

Submit your next manuscript at $\boldsymbol{\nabla}$ springeropen.com 